\title{
ANALYSIS OF SYSTEMS UNDER PROBABILISTIC AND FUZZY UNCERTAINTY USING MULTIVALUED LOGIC
}

\author{
Alexander Gegov \\ University of Portsmouth \\ Portsmouth, United Kingdom \\ Daniela Parashkevova, Krum Ljubenov \\ University of Mining and Geology \\ Sofia, Bulgaria
}

\section{SUMMARY}

This paper introduces a special class of functions characterised by two reciprocally connected mappings - logical and probabilistic. The adequacy of this formal instrument is established through input-output sets of data from real multifactor multistage plants operating under stochastic and fuzzy uncertainty of the environment. It is shown how incorrect data can be successfully processed for prediction and control purposes by applying interpolation, composition and extrapolation procedures to the above class of functions.

\section{KEY WORDS}

Probability theory, fuzzy sets, probabilistic-fuzzy uncertainty, multi-valued logical probabilities, probabilistic-fuzzy functions.

\section{INTRODUCTION}

The complex control objects and systems are characterized by stochastic and fuzzy indeterminacy while the correlation between them and their influence upon the output cannot be established. As a result of objectively emerged (arisen) difficulties in delimitation (differentiation) and description of the two basic types indeterminacy, in practice one of them is eliminated in favor of statistic-probability methods or respectively the fuzzy multitude methods, correlation etc. This inadequacy between indeterminacy nature and the applied conceptions and methods (have a negative effect) exert negative influence on the effectiveness of obtained models and applied procedures.

The emphasized considerations are a sufficient ground new concepts and methods for compatible description of the two basic types indeterminacy probability and fuzzy to be searched for.

The successful development of these conceptions and methods are basic for overcoming the third indeterminacy form, originated by lack of knowledge.

A considerable number of formulations, concepts and modeling -control methods in the conditions of probability or fuzzy indeterminacy are known. The latter have their considerable advantages and disadvantages, fields of appliance $[1,2,3,15]$.

Precise evaluation and comparison of both are practically impossible because circumstances, characteristics and problems are versatile and each specific characteristic of the researched object and its function area are in practice very 
essential for the successful solution of the arising problems. The evaluation and comparison of the available conceptions and methods is obviously a subject of wide research, which is not a goal of present paper. As offset of these problems, the introduced in 1968 by L.Zade concept - fuzzy event through the axiomatic probability theory, should be considered.

The present paper offers a summary and development of methods, based on joint application of multivalue logic functions and probability theory $[4,5,6,7,8,9]$. They are applied for research and control processes in mineral technologies (flotation of copper ores) and prognosis of technological processes.

\section{INDETERMINACY CLASSIFICATION}

The following categories and definitions are adapted:

- Indeterminacy - meaning lack of knowledge. This class of determinacy is subject of philosophy and of theory of knowledge, therefore not discussed in this paper.

- Fuzzy indeterminacy determined by violation of identity axioms at the time of object identification. This violation results from inaccurate knowledge, definitions, subjectivism and lack of reliable methods and/or technical means for measurement, identification and classification.

- Random indeterminacy, subject to joint action of a big number uncontrollable factors, events, and phenomena of stochastic character.

- Combination of presented three-valued kind of indeterminay. Most frequently real control objects combine fuzzy and stochastic indeterminacy in different correlation.

\section{MULTIVALUED LOGICAL PROBABILITY FUNCTIONS (MLPF)}

The examined function class is characterized by two relevancies between multitude of arguments $X \quad\left\{x_{1}, x_{2}, \ldots, x_{n}\right\}$ and of function $y=f(X): \operatorname{logic}$ and probable. The logical relevance is determined in $k$-valued logic system $(k \geq 3)$ by means of which to each element of the definition field are compared $k$ number elements $y_{j}, j=1 \div k$ of the function $y=f(X)$, belonging to the definition field.

The multitude arguments $x_{i}, \quad i=1 \div n$, as well as the function $y_{j}, \quad j=1 \div k$ have values in $k$-element multitude of logic values $A_{k}\left(a_{1}, a_{2}, \ldots, a_{k}\right)$. Logic values $a_{1}, a_{2}, \ldots, a_{k}$ are possible to have different meanings depending on the problems (tasks) and apriori information about the researched object (process): intervals of numerical values (minimal and maximal), fixed numerical or logical values (levels), final differences (changes of numerical values), qualitative values etc. The most adequate form for setting of logic compliance is the table form, analogy to the table of truth (veracity, authenticity) in classical logic systems. The probability compliance between sets of arguments $x_{i}$, $i=1 \div n$ of the multitude $A_{k}$ and the values of function $y_{j}, j=1 \div k$ of same multitude $A_{k}$, through adequately chosen probability measure could be set a probability 
matrix $P=\left\{p_{s j}\right\}$, where $s=1 \div M$ is the set number, $M=k^{n}$ is number of possible sets of arguments $x_{i}, \quad i=1 \div n, j=1 \div k$. In short MLPF is noted with the symbol \&, $y=f(X) \& P\{X\}$.

Example 1. Multivalued logical probability function $y=f(X) \& P\{X\}$ of two arguments $x_{1}, x_{2} \quad(n=2)$, formed in three-valued logic system $(k=3)$ through multitude of logic values $A_{3}\left(a_{1}, a_{2}, a_{3}\right)$ and probabilities $p_{s j}, s=1 \div 9, j=1 \div 3$ are given in table 1 . To each column with number $s$ corresponds a set of logical arguments $x_{1}$ and $x_{2}$ and probabilities $p_{s j}$ for realization of the logical values of function $y_{j}$ : value $a_{1}$ with probability $p_{s 1}$, value $a_{2}$ with probability $p_{s 2}$, value $a_{3}$ with probability $p_{s 3}, s=1 \div 9$. For each set $s$ exist a maximal $\left(p_{s j}=\max \right)$ and minimal $\left(p_{s j}=\min \right)$ probability for possible values $y_{j}$ of function $y$.

Multivalued logical probability function $y=f(X) \& P\{X\}$

\begin{tabular}{|c|c|c|c|c|c|c|c|c|c|c|}
\hline \multicolumn{2}{|c|}{$s$} & $\boldsymbol{1}$ & $\mathbf{2}$ & $\mathbf{3}$ & $\mathbf{4}$ & $\mathbf{5}$ & $\mathbf{6}$ & $\mathbf{7}$ & $\boldsymbol{8}$ & $\mathbf{9}$ \\
\hline \multicolumn{2}{|c|}{$x_{1}$} & $a_{1}$ & $a_{1}$ & $a_{1}$ & $a_{2}$ & $a_{2}$ & $a_{2}$ & $a_{3}$ & $a_{3}$ & $a_{3}$ \\
\hline \multicolumn{2}{|c|}{$x_{2}$} & $a_{1}$ & $a_{2}$ & $a_{3}$ & $a_{1}$ & $a_{2}$ & $a_{3}$ & $a_{1}$ & $a_{2}$ & $a_{3}$ \\
\hline \multirow{3}{*}{$y$} & $a_{1}$ & $p_{11}$ & $p_{21}$ & $\ldots$ & $\ldots$ & $\ldots$ & $\ldots$ & $\ldots$ & $\ldots$ & $\ldots$ \\
\cline { 2 - 13 } & $a_{2}$ & $p_{12}$ & $\ldots$ & $\ldots$ & $p_{42}$ & $\ldots$ & $\ldots$ & $\ldots$ & $\ldots$ & $\ldots$ \\
\cline { 2 - 12 } & $a_{3}$ & $p_{13}$ & $\ldots$ & $\ldots$ & $\ldots$ & $p_{s j}$ & $\ldots$ & $\ldots$ & $p_{83}$ & $p_{93}$ \\
\hline \multicolumn{2}{|c|}{$p_{s j}=\max$} & $p_{12}$ & $\ldots$ & $\ldots$ & $\ldots$ & $\ldots$ & $p_{61}$ & $\ldots$ & $\ldots$ & $\ldots$ \\
\hline \multicolumn{2}{|c|}{$p_{s j}=\min$} & $p_{13}$ & $\ldots$ & $\ldots$ & $\ldots$ & $\ldots$ & $p_{63}$ & $\ldots$ & $\ldots$ & $\ldots$ \\
\hline
\end{tabular}

\section{CHARACTERISTICS OF MLPF}

- Logical values of function $y$ for each set of values of argument $X$ are incompatible accidental events $a_{j}, j=1 \div k$, that form a full group: $\sum_{j=1}^{k} p_{s j}\left(a_{j}\right)=1$ for each $s=1 \div M$.

- MLPF is fully set if all elements of the probability matrix $\left\{p_{s j}\right\}$ are known. In contrary case a procedure of logical probability interpolation is carried out, described in point 7.

- For each set $s$ logical values of arguments $x_{i}, \quad i=1 \div n$ exist at least one minimal and one maximal value of probabilities $p_{s j}\left(a_{j}\right), j=1 \div k$ concerning the logical values $y_{j}$ of function $y$.

- Each MLPF of $n$ number arguments, set in $k$-value logical system generates system of $L=k \cdot k^{k^{n}}$ number alternative MLPF.

- The system of $L$ number alternative MLFP has at least one function, which for each set of values $s=1 \div M$ of arguments $x_{i}$ is characterized with maximal probabilities $p_{s j}\left(a_{j}\right), j=1 \div k$. It expresses the basic logical 
and probability dependence between arguments $X$ and function $y$ and is called basic function of MLPF.

- Through adequate logical and probability measure, the degree of

- deviation between the basic and the rest alternative MLPF is defined. The degree of deviation determines the expedience ( advisability) from introduction of bigger or lesser number alternative functions by systematic investigations of object, by development (elaboration) of interval prognosis etc.

- MLPF create conditions for joint description of probability and logical indeterminacy. It is appropriate to evaluate the degree of probability and logical indeterminacy through the entropy expression:

$$
H_{s}=-\sum_{j=1}^{k} p_{s j} \log _{2} p_{s j},[b i t], \quad s=1 \div M
$$

The indeterminacy is different for each set of logical values of arguments $x_{i}$. The logical indeterminacy is defined by the number of significant values $y_{j}$ of function $y$.

- The degree of indeterminacy for all sets logical values of arguments $x_{i}$ are calculated with the entropy average value for the multitude sets of arguments $x_{i}$ :

$$
H\{y\}=-\frac{1}{M} \sum_{s=1}^{M} \sum_{j=1}^{k} p_{s j} \log _{2} p_{s j},[b i t]
$$

where $M=k^{n}$ is the set number.

Alternative MLPF with rapid increasing degree of indeterminacy is admissible to be eliminated (excluded) from the following stages of object researches as they are unreliable and with low information.

- It is desirable MLPF to be examined for availability ( presence) of commanding and fictive arguments, for possibilities of decomposition and aggregation (composition), for minimization and etc.

\section{FORMULATION METHODS FOR MLPF}

In essence MLPF are a compact organized basis of knowledge about the examined (researched) object. Sources for formulation of logical and probability dependence between arguments and function are:

- Process theory if such is available. In case of availability of multifactor analytical dependences, they are discretetized through numerical methods, limit differences etc. after which they are transformed in relevant logical values (levels), logical changes of values and respective function are formed.

- Expert knowledge

- Statistical methods

- Joint application of theory, expert knowledge and statistics. 


\section{ANALYTICAL MLFP FORM}

The table MLFP form, in particular by great number of arguments and more considerable significance of logical system is difficult to be defined. For transformation the table into analytical form, appropriately chosen axiomatics is introduced. The analytical form of a basic or alternative logical probability function has the following general expression:

$$
y=f(X) \& P\{f(X)\}=\left\{\begin{array}{l}
a_{j} \text { with probability } p_{a j}=\min \left(p_{s j}\right), s=1 \div M, \\
\text { when } D_{a_{j}}(X)=K_{a_{j}}^{(1)}(X) \vee K_{a_{j}}^{(2)}(X) \vee \ldots=a_{j} \\
j=1 \div k
\end{array}\right\}
$$

where $D_{a j}(X)$ is disjunction in $k$-numbered logical system, $K_{a j}^{(s)}(X)$ is conjunction composed for the $s$ - set of argument values $x_{i}$, where the function $y$ has a logical value $a_{j}, \quad j=1 \div k$.

Example 2. Basic MLFP is shown in table 2. In the fourth table row are given the values of function $a_{j}, j=1 \div k$ and the relative probabilities (maximal) $p_{s j}$.

\section{Basic MLFP}

Table 2

\begin{tabular}{|c|c|c|c|c|c|c|c|c|c|}
\hline$s$ & $\mathbf{1}$ & $\mathbf{2}$ & $\mathbf{3}$ & $\mathbf{4}$ & $\mathbf{5}$ & $\mathbf{6}$ & $\mathbf{7}$ & $\boldsymbol{8}$ & $\mathbf{9}$ \\
\hline$x_{1}$ & $a_{1}$ & $a_{1}$ & $a_{1}$ & $a_{2}$ & $a_{2}$ & $a_{2}$ & $a_{3}$ & $a_{3}$ & $a_{3}$ \\
\hline$x_{2}$ & $a_{1}$ & $a_{2}$ & $a_{3}$ & $a_{1}$ & $a_{2}$ & $a_{3}$ & $a_{1}$ & $a_{2}$ & $a_{3}$ \\
\hline$y_{j}$ & $a_{2} / p_{12}$ & $a_{1} / p_{21}$ & $a_{1} / p_{31}$ & $a_{2} / p_{42}$ & $a_{3} / p_{53}$ & $a_{1} / p_{61}$ & $a_{3} / p_{73}$ & $a_{2} / p_{82}$ & $a_{1} / p_{91}$ \\
\hline
\end{tabular}

The analytical form of basic MLFP will be:

$$
y=\left\{\begin{array}{l}
a_{1} \text {, with probability } p_{a_{1}}=\min \left(p_{21}, p_{31}, p_{61}, p_{91}\right), \\
\text { when } D_{a_{1}}(X)=x_{1} \cdot 2 N x_{2} \vee x_{1} \cdot N x_{2} \vee 2 N x_{1} \cdot N x_{2} \vee N x_{1} \cdot N x_{2}, \\
a_{2}, \text { with probability } p_{a_{2}}=\min \left(p_{12}, p_{42}, p_{82}\right), \\
\text { when } D_{a_{2}}(X)=N x_{1} \cdot N x_{2} \vee x_{1} \cdot N x_{2} \vee 2 N x_{1} \cdot x_{2}, \\
a_{3} \text {, with probability } p_{a_{3}}=\min \left(p_{53}, p_{73}\right), \\
\text { when } D_{a_{3}}(X)=N x_{1} \cdot N x_{2} \vee x_{1} .2 N x_{2},
\end{array}\right.
$$

where $N$ is a negative symbol, $2 N-$ double cycle negative.

\section{MLFP INTERPOLATION}

The above-indicated characteristics of the examined function class create conditions for valid (substantiated) evaluation of probabilities for realization of function $y$ values, when they are not present (are missing) in MLFP table for separate sets of arguments $x_{i}$, e.g. carrying out of logical-probability interpolation. A ground for a successful carrying out of interpolation is the availability of basic and alternative functions, whose data are examined as: 
a) initial conditions for existing relations between the elements of set (given) compositions (theoretic-multiple approach);

b) initial conditions for calculating of complex event probabilities (approach based on probability theory);

If we suppose that MLFP from table 1 is unknown for the set $s=5$ $\left(x_{1}=a_{2}, x_{2}=a_{2}\right)$. Interpolation in this "point" is carried out according concrete probability values (relations) for $s=4$ and $s=6$ in case of indefinite situation the procedure is extended (broadened) with the relations (or probabilities) between MLFP values for $s=1$ and $s=3$ besides for $s=7$ and $s=9$. Undeniably possible are multitudes of concrete probabilities and relations, but it is impossible here to analyze in details all possible situations. In case of big number arguments $x_{i}, \quad i=1 \div n$ conditions for higher reliability and objective evaluation of indeterminacy are created.

In the examined elementary example the following procedure is applied:

Relations and probabilities between situations $s_{4}$ and $s_{6}$.

The following situations are possible ( table 1):

a) $p_{41}\left(a_{2}, a_{1}\right)_{<}^{2} p_{61}\left(a_{2}, a_{3}\right)$;

b) $p_{42}\left(a_{2}, a_{1}\right)_{<}^{2} p_{62}\left(a_{2}, a_{3}\right)$;

C) $p_{43}\left(a_{2}, a_{1}\right)_{<}^{2} p_{63}\left(a_{2}, a_{3}\right)$.

In case of strongly expressed relation of commanding the variable $x_{2}=$ var with $x_{1}=$ const $=a_{2}$ the unknown probability $p_{51}$ will be within the interval $p_{41} \div p_{61}$ and with high level of probability will be closer to probability $p_{41}$. In case of equivalent relation, the probability $p_{51}$ for $y=a_{1}$ will have a value close to their average arithmetical value etc. By analogy it is proceeded and for values of the function $y=a_{2}$ and $y=a_{3}$.

When the relation is not obviously expressed by analogy the analysis is filled out with relations and probabilities between $s_{1}$ and $s_{2}, s_{7}$ and $s_{9}$. In case of lack of clearly expressed relations or differentiated probabilities methods of statistical tests are applied.

\section{MLFP COMPOSITION}

Composition of two MLFP is an operation which defines the probability distribution of logical values of the second (next in position) MLFP as a result of probability distribution of values of the first (previous) of composed MLFP. The composition of a greater number of MLFP is an operation in the course of which all following in position functions obtain probability distribution of their logical values by analogy of previous functions. The composition is noncommutative as it is dependent on the dimension of the variables $X$ and $Y$. This composition is possible when MLFP are correctly set: the logical function $F(X)$ does not contain fictive variables, contradictory values etc.; the 
probability matrix $P\{F(X)\}$ satisfies the characteristics related to occasional events forming a whole group.

One MLFP is in essence a model of a definite real system. The forming of function $F(X, W)$ and of matrix $P\{F(X, W)\}$ is a description of established (systems) it is essential the elements of the matrix $P\{F(X, W)\}$ to be renewed in real time, for example through frequency of realization of outputs $Y$ for the newly appeared sets from the realization of $X$ and $W$. In lack of appearance of some sets an expert evaluation of specialist in the field or interpolation on basis of the newly appeared sets are applied, according previous point 7.

Criteria for matrix adequacy are the prognosis possibilities of model (MLFP).

The table form of the first composed MLFP is partially shown in table 3.

$$
Y=F_{1}\left(x_{1}, x_{2}, w_{1}, w_{2}\right) \& P\left\{F_{1}\left(x_{1}, x_{2}, w_{1}, w_{2}\right)\right\}
$$

\begin{tabular}{|c|c|c|c|c|c|c|c|}
\hline & & & & & & & e \\
\hline Set & & 1 & 2 & 3 & 4 & 5 & 6 \\
\hline $\begin{array}{c}\text { Prob } \\
p_{s j}\end{array}$ & ty & $p_{s 1}$ & $p_{s 2}$ & $p_{s 3}$ & $p_{s 4}$ & $p_{s 5}$ & $p_{s 6}$ \\
\hline & & $a_{1}$ & $a_{1}$ & $a_{1}$ & $a_{1}$ & $a_{1}$ & $a_{1}$ \\
\hline & & $a_{1}$ & $a_{1}$ & $a_{1}$ & $a_{1}$ & $a_{1}$ & $a_{1}$ \\
\hline & & $a_{1}$ & $a_{1}$ & $a_{1}$ & $a_{2}$ & $a_{3}$ & $a_{3}$ \\
\hline & & $a_{1}$ & $a_{2}$ & $a_{3}$ & $a_{1}$ & $a_{1}$ & $a_{2}$ \\
\hline & $a_{1}$ & $p_{11}$ & $p_{21}$ & $p_{31}$ & $p_{41}$ & $p_{51}$ & $p_{61}$ \\
\hline$y$ & $a_{2}$ & $p_{12}$ & $p_{22}$ & $p_{32}$ & $p_{42}$ & $p_{52}$ & $p_{62}$ \\
\hline & $a_{3}$ & $p_{13}$ & $p_{23}$ & $p_{33}$ & $p_{43}$ & $p_{53}$ & $p_{63}$ \\
\hline
\end{tabular}

The function is shown(presented) in three numbered logic system $(k=3)$ with elements of the multitude $A_{3}\left(a_{1}, a_{2}, a_{3}\right)$ where $a_{1}, a_{2}, a_{3}$ are logical values, for instance $a_{1}$ - low value, $a_{2}$ - normal value, $a_{3}$ - high value. These values have variables $x_{1}, x_{2}, w_{1}, w_{2}$ and $y$. The argument number is $n=n_{1}+n_{2}=2+2=4$; the number of sets of arguments $(X, W)$ is $k^{n}=3^{4}=81$. On table 3 are given only 6 sets for obvious reasons. The probabilities of sets are marked with $p_{s 1}, p_{s 2}, p_{s 3}, \ldots, p_{s 81}$. They are a combination (totality) of independent and incompatible occasional events that compose full group e.g. their sum is equal to one. For each separate (concrete) set of arguments $(j=1,2, \ldots, 81)$ it is possible the function $y$ to have $k=3$ values $\left(a_{1}, a_{2}, a_{3}\right)$ with the corresponding probabilities $p_{j i}, i=1,2,3, j=1,2, \ldots, 81$, which are elements of matrix $P\left\{F_{1}(X, W)\right\}$. MLFP composed with function $Y=F_{1}(X, W) \& P\left\{F_{1}(X, W)\right\}$ (table 3) are marked through $Z=F_{2}(Y, V) \& P\left\{F_{2}(Y, V)\right\}$. It is shown on table 4 . 
Table 4

\begin{tabular}{|c|c|c|c|c|c|c|c|}
\hline \multicolumn{2}{|c|}{ Set $j$} & 1 & 2 & 3 & 4 & 5 & 6 \\
\hline \multicolumn{2}{|c|}{ Probability $q_{l j}$} & $q_{l 1}$ & $q_{l 2}$ & $q_{l 3}$ & $q_{l 4}$ & $q_{l 5}$ & $q_{l 6}$ \\
\hline \multicolumn{2}{|c|}{$y$} & $a_{1}$ & $a_{1}$ & $a_{1}$ & $a_{1}$ & $a_{1}$ & $a_{1}$ \\
\hline \multicolumn{2}{|c|}{$v_{1}$} & $a_{1}$ & $a_{1}$ & $a_{1}$ & $a_{1}$ & $a_{1}$ & $a_{1}$ \\
\hline \multicolumn{2}{|c|}{$v_{2}$} & $a_{1}$ & $a_{1}$ & $a_{1}$ & $a_{2}$ & $a_{3}$ & $a_{3}$ \\
\hline \multicolumn{2}{|c|}{$v_{3}$} & $a_{1}$ & $a_{2}$ & $a_{3}$ & $a_{1}$ & $a_{1}$ & $a_{2}$ \\
\hline \multirow{3}{*}{$z$} & $a_{1}$ & $q_{11}$ & $q_{21}$ & $q_{31}$ & $q_{41}$ & $q_{51}$ & $q_{61}$ \\
\hline & $a_{2}$ & $q_{12}$ & $q_{22}$ & $q_{32}$ & $q_{42}$ & $q_{52}$ & $q_{62}$ \\
\hline & $a_{3}$ & $q_{13}$ & $q_{23}$ & $q_{33}$ & $q_{43}$ & $q_{53}$ & $q_{63}$ \\
\hline
\end{tabular}

The distribution matrix of probabilities of second MLFP is noted with $Q\left\{F_{2}\left(y, v_{1}, v_{2}, v_{3}\right)\right\}$ and is enclosed with thick lines. The probabilities of set realizations are noted (marked) with $q_{l 1}, q_{l 2}, q_{l 3}, \ldots, q_{l j}$ and the probabilities of function values $Z$ with $q_{l j}$ (elements of matrix $Q\left\{F_{2}(Y, V)\right\}$ ).

9. MATRIX CHARACTERISTICS OF FUNCTIONS $F_{1}(X, W)$ AND $F_{2}(Y, V)$, AND OF PROBABILITIES DISTRIBUTIONS $P\left\{F_{1}(X, W)\right\}$ AND $Q\left\{F_{2}(Y, V)\right\}$

9.1 As a result of independent occasional events at the input of system $X$ and the contacts of same with the outer medium $W$ and $V$ and the circumstance that the sets of events $X, W$ and $V$ are incompatible and form a full group, the following dependencies are valid:

$\sum_{i=1}^{k} p_{j i}=1 \quad$ for each $j=1,2, \ldots, k^{n_{1}}$;

(1)

$\sum_{i=1}^{k} q_{j i}=1 \quad$ for each $j=1,2, \ldots, k^{n_{2}}$,

(2)

where $p_{s i}$ and $q_{l i}$ are elements of matrix $P\left\{F_{1}(X, W)\right\}$ and respectively $Q\left\{F_{2}(Y, V)\right\}$.

9.2. For probabilities of sets $p_{s j}$ and $q_{l j}$ of arguments $X, W$ and respectively $Y, V$.

$$
\sum_{j=1}^{k^{n_{1}}} p_{s j}=1 ; \quad \sum_{j=1}^{k^{n_{2}}} q_{l j}=1
$$

9.3. Probability $p_{y i}$ for realization of function $y=a_{i}, i=1,2, \ldots, k$ is product of probability $p_{s j}$ for realization of set $(X, W)$ with probability $p_{j i}$ : 
$p_{y_{i}}=P\left\{y=a_{i}\right\}=p_{s j} \cdot p_{s i}, \quad j=1,2, \ldots, k^{n_{1}} \quad$ for each $\quad i=1,2, \ldots, k$

9.4. Probability $q_{z i}$ for realization of function $Z=a_{i}, i=1,2, \ldots, k$ is product of probability $q_{l j}$ for realization of set $(Y, V)$ with probability $q_{j i}$ :

$$
q_{z_{i}}=P\left\{z=a_{i}\right\}=q_{l j} \cdot q_{j i}, \quad j=1,2, \ldots, k^{n_{2}} \quad \text { for each } \quad i=1,2, \ldots, k
$$

9.5. Probabilities of sets $q_{l j}$ in function $Z$ (table 2) prior to its composition are unknown, because they depend on distribution of probabilities $p_{y i}$, $i=1,2, \ldots, k$.

\section{EXTRACTION (OBTAINING) OF NEW KNOWLEDGE ABOUT THE OBJECT BEHAVIOR}

Interpolation of MLFP is in essence a procedure for extraction of new knowledge in a definite limited field of object behavior. The possible inaccuracies concerning these knowledge are connected with the probabilities, through which the logical values of multitude $A_{k}$ are realized and they are subject to remodification (respecifying) in the process of object functioning.

Through composition of MLFP new knowledge, about the object in wider field is obtained.

Diagnostics for appearance of contradictory or incompatible sets from inputoutput data e.g. production principle (elementary knowledge) is the appearance of incorrectness of interpolation and/or composition procedures.

\section{DESCRIPTION AND RESEARCH OF SYSTEMS WITH PROBABILIY AND FUZZY INDETERMINACY THROUGH MULTIVALUED LOGICAL PROBABILITY FUZZY FUNCTIONS (MLPFF)}

The above described definitions and characteristics of MLFP and the applied procedures (interpolation, composition) are instrument for formal description, analysis, prognosis, control of complex objects and systems that are characterized with great number stochastic factors, with non-stationary, multiple etc.

The submitted (offered) class functions are models of objects (systems) in established regime in relation to the controlling influences as $W\left(w_{1}, w_{2}, \ldots, w_{r}\right)$. The non-stationary of outputs $Y\left(y_{1}, y_{2}, \ldots, y_{m}\right)$ and/or conditions $Z\left(z_{1}, z_{2}, \ldots, z_{e}\right)$ are defined by controllable factors $X\left(x_{1}, x_{2}, \ldots, x_{n}\right)$ and the summary (compendious) multitudes by uncontrollable disturbances of $\xi(t)$ medium. Dynamic models through MLFP are object of supplementary constructions, definitions, characteristics etc. and are not examined in this paper. When the input or input-output data about the processes in the object are inaccurate and are examined as fuzzy MLFP, they are transformed in MLPFF. Normal is the 
introduction of logic linguistic variables for controllable factors $X$ and for outputs $Y$, while the control influences $W$ to be examined as exact numeric or logic variables. A new element is the dimension growth (increase) of vectors $X$ and $Y$. The number of accepted logic-linguistic values defines this growth. For a clearer exposition, an example with $k=3$ basic logic values is described: low $(L)$, standard $(S)$, high $(H)$ values. Appurtenance functions for all variables $x_{1}, x_{2}, \ldots, x_{n}, y_{1}, y_{2}, \ldots, y_{m}$ are typical trapezium with standard zones of (?).

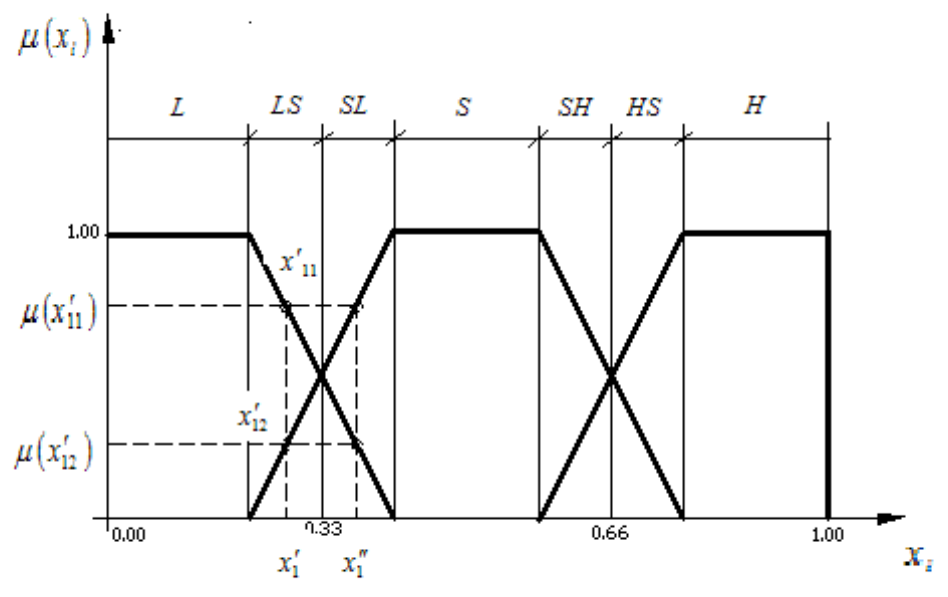

Figure 1

On figure 1 is shown an appurtenance function $\mu\left(x_{i}\right)$ of factor $x_{i}, i=1,2, \ldots, n$. By accepted three valued logic function $(k=3)$ the number of logic-linguistic values is $k_{L L V}=7$ : low $(L)$, low-standard $(L S)$, standard-low $(S L)$, standard $(S)$ standard-high $(S H)$, high-standard $(H S)$, high $(H)$. When factor $x_{i}$ has an incorrectly measured value $x_{1}^{\prime}$, obviously $\mu\left(x_{11}^{\prime}\right)>\mu\left(x_{12}^{\prime}\right)$. Semantically founded is the logic-linguistic value of factor $x_{i}$ to be low-standard $(L S)$ e.g. nearer to low value $(L)$. When the inaccurately measured values is $x_{1}^{\prime \prime}$ the logic-linguistic value of factor $x_{i}$ is standard-low $(S L)$. The same is applied and to interstitial (medial) values $(S H)$ and $(H S)$. The introducing of analytic dependence for the two values of the two values of $\mu\left(x_{11}^{\prime}\right)$ and $\mu\left(x_{12}^{\prime}\right)$ in table form of MLPFF is non-informative and redundant. Therefore only the higher value of appurtenance level of corresponding factor is introduced.

On table 5 is shown the type of table form of one MLPFF. It includes the set number $(s)$ of input influences (control $W$, factors $X$ ), probability $p(s)$ for realization of corresponding set (this information is not a must in all cases), logic-linguistic values of all input influences and output of object (system), probabilities for realization $p_{\text {sdl }}$ and level of appurtenance $\mu_{\text {sdl }}$ of object outputs for the corresponding set $s$. Here the index $d$ defines the serial number of output and the index $l$ defines the logic-linguistic value of realized output.

To make things clearer and shorter MLPFF of table 5 defines an object with two control influences $w_{1}$ and $w_{2}$, two vectors of medium $x_{1}$ and $x_{2}$, and two 
outputs $y_{1}$ and $y_{2}$. Only limited number of sets $(s=1 \div 8)$ are shown, as the full number sets is $k \cdot k^{(n+2)}$, where valued of logical system is $(k=7)$, factors are $n=2$ and controls $r=2$. The full number of sets is theoretical, as it is possible that some of them are not admissible due to physical or technical conditions for functioning of object. It is possible that probability for realization $p(s)$ of some sets to be insignificant and therefore their elimination. By appearance of their necessity these values should be obtained by interpolation on basis of the closest available sets.

Table form of multivalued logic fuzzy probability function

Table 5

\begin{tabular}{|c|c|c|c|c|c|c|c|c|c|}
\hline \multirow{2}{*}{\multicolumn{2}{|c|}{$\begin{array}{l}\text { Set }(s) \\
\text { Probability } \\
\left(p_{s}\right)\end{array}$}} & 1 & 2 & 3 & 4 & 5 & 6 & 7 & 8 \\
\hline & & $L$ & $L$ & $L$ & $L$ & $L$ & $L$ & $L S$ & $L S$ \\
\hline \multicolumn{2}{|c|}{$w_{1}$} & $L$ & $L$ & $L$ & $L$ & $L$ & $L S$ & $L S$ & $S$ \\
\hline \multicolumn{2}{|c|}{$w_{2}$} & $L$ & $L$ & $L$ & $L$ & $L S$ & $L S$ & $S$ & SH \\
\hline \multicolumn{2}{|c|}{$x_{1}$} & $L$ & $L$ & $L$ & $L S$ & $S$ & $S H$ & $S H$ & $S H$ \\
\hline \multicolumn{2}{|c|}{$x_{2}$} & $L$ & $L S$ & $S$ & $H S$ & $H S$ & $S$ & $L S$ & $L S$ \\
\hline \multirow{7}{*}{$y_{1}$} & $L$ & $p_{11 L} / \mu_{11 L}$ & $\cdots$ & $\cdots$ & $\cdots$ & $\cdots$ & $\cdots$ & $\cdots$ & $\cdots$ \\
\hline & $L S$ & $p_{11 L S} / \mu_{11 L S}$ & $\begin{array}{c} \\
\cdot\end{array}$ & $\cdots$ & $\begin{array}{c} \\
\cdot\end{array}$ & $\cdots$ & $\begin{array}{c} \\
\cdot\end{array}$ & & 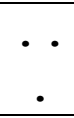 \\
\hline & $S L$ & $\ldots$ & $\begin{array}{c}\cdots \\
.\end{array}$ & $p_{s d l} / \mu_{s d l}$ & $\begin{array}{c}\cdots \\
.\end{array}$ & $\cdots$ & $\begin{array}{c}\cdots \\
.\end{array}$ & $\begin{array}{c}\cdots \\
.\end{array}$ & $\begin{array}{c}\cdots \\
.\end{array}$ \\
\hline & $S$ & . . & $\begin{array}{c}\cdots \\
\cdot\end{array}$ & $\cdots$ & $\begin{array}{c}\cdots \\
\cdot\end{array}$ & $\cdots$ & $\begin{array}{c}\cdots \\
\cdot\end{array}$ & $\begin{array}{c}\cdots \\
\cdot\end{array}$ & $\begin{array}{c}\cdots \\
\cdot\end{array}$ \\
\hline & SH & $\cdots$ & $\begin{array}{c}\cdots \\
.\end{array}$ & $\cdots$ & $\begin{array}{c}\cdots \\
.\end{array}$ & $\cdots$ & $\begin{array}{c}\cdots \\
.\end{array}$ & $\begin{array}{c}\cdots \\
.\end{array}$ & $\begin{array}{c}\cdots \\
.\end{array}$ \\
\hline & $H S$ & $\ldots$ & $\begin{array}{l}\cdots \\
.\end{array}$ & . & $\begin{array}{c}\cdots \\
\cdot\end{array}$ & $\cdots$ & $\begin{array}{c}\cdots \\
\cdot\end{array}$ & $\begin{array}{c}\cdots \\
\cdot\end{array}$ & $\begin{array}{c}\cdots \\
\cdot\end{array}$ \\
\hline & $H$ & $p_{11 H} / \mu_{11 H}$ & $\begin{array}{l}\cdots \\
.\end{array}$ & $\cdots$ & $\begin{array}{c}\cdots \\
\cdot\end{array}$ & $\cdots$ & $\begin{array}{c}\cdots \\
\cdot\end{array}$ & $\begin{array}{c}\cdots \\
\cdot\end{array}$ & $\begin{array}{c}\cdots \\
\cdot\end{array}$ \\
\hline \multirow{7}{*}{$y_{2}$} & $L$ & $p_{12 L} / \mu_{12 L}$ & $\begin{array}{l}\cdots \\
\cdot\end{array}$ & $\cdots$ & $\cdots$ & $\cdots$ & $\cdots$ & $\cdots$ & • \\
\hline & $L S$ & $\cdots$ & $\begin{array}{c}\cdots \\
\cdot\end{array}$ & $\cdots$ & $\begin{array}{c}\cdots \\
\cdot\end{array}$ & $\cdots$ & $\begin{array}{c}\cdots \\
\cdot\end{array}$ & $\begin{array}{c}\cdots \\
\cdot\end{array}$ & $\begin{array}{c}\cdots \\
\cdot\end{array}$ \\
\hline & $S L$ & $\cdots$ & $\begin{array}{c}\cdots \\
\bullet\end{array}$ & $\cdots$ & $\begin{array}{c}\cdots \\
\cdot\end{array}$ & $\cdots$ & $\begin{array}{c}\cdots \\
\cdot\end{array}$ & $\begin{array}{c}\cdots \\
\cdot\end{array}$ & $\begin{array}{c}\cdots \\
\bullet\end{array}$ \\
\hline & $S$ & $\ldots$ & . & $\cdots$ & $\begin{array}{c}\cdots \\
.\end{array}$ & . & $\begin{array}{c}\cdots \\
.\end{array}$ & $\begin{array}{c}\cdots \\
\cdot\end{array}$ & $\begin{array}{c}\cdots \\
\cdot\end{array}$ \\
\hline & SH & $\cdots$ & $\begin{array}{c}\cdots \\
\cdot\end{array}$ & $\cdots$ & $\begin{array}{c}\cdots \\
\cdot\end{array}$ & $p_{s d l} / \mu_{s d l}$ & $\begin{array}{c}\cdots \\
\cdot\end{array}$ & $\begin{array}{c}\cdots \\
\cdot\end{array}$ & $\begin{array}{c}\cdots \\
\cdot\end{array}$ \\
\hline & $H S$ & $\cdots$ & $\begin{array}{c}\cdots \\
\cdot\end{array}$ & $\cdots$ & $\begin{array}{c}\cdots \\
\cdot\end{array}$ & $\cdots$ & $\begin{array}{c}\cdots \\
\cdot\end{array}$ & $\begin{array}{c}\cdots \\
\cdot\end{array}$ & $\begin{array}{c}\cdots \\
\cdot\end{array}$ \\
\hline & $H$ & $p_{12 H} / \mu_{11 H}$ & $\begin{array}{c}\cdots \\
\cdot\end{array}$ & $\cdots$ & $\begin{array}{c}\cdots \\
\cdot\end{array}$ & $\cdots$ & $\begin{array}{c}\cdots \\
\cdot\end{array}$ & $\begin{array}{c}\cdots \\
\cdot\end{array}$ & $\begin{array}{c}\cdots \\
\cdot\end{array}$ \\
\hline
\end{tabular}


All characteristics of MLFP concerning probabilities $p_{\text {sdl }}$ are relied and to MLPFF. By processing of appurtenance level $\mu_{\text {sdl }}$ the operations and characteristics of fuzzy multitudes and relations are applied.

\section{CONCLUSION}

A method for research of multifactor, multiple, non-stationary including multilevel objects (systems) is developed. It is based on combination of mutually connected logic and probability correspondences The method is applicable and by fuzzy indeterminacy of input and output data and their dependences.

\section{IITERATURE}

1. Аоки М. Оптимизация стохастических систем. Москва, Наука, 1971.

2. Евланов Л.Г., В.М. Константинов Системы со случайными параметрами. Москва, Наука, 1976.

3. Куржанский А.Б. Управление и наблюдение в условиях неопределенности. Москва, Наука, 1977.

4. Гегов Е. Въведение в системните изследвания и логически методи за моделиране. Трудове на МГУ, София, 1993.

5. Гегов Е. Логический подход и метод прогнозирования многофакторных процессов, 16-ти Всемирный Горный Конгрес, т.2, доклад С-34, 289-293с.

6. Гегов Е. Прогнозиране на процеси на многофакторни обекти и системи посредством селекция на логически вероятностни функции, Национална конференция АВТОМАТИКА*94. Сборник научни трудове, София, 1995 , 203-205c.

7. Гегов Е. Моделирование систем методом логических размитых функции одного класса. Logic and Applications, Vol.IV, International Interdisciplinary Symposium on Logic, 1994, 3-5.

8. Gegov E., A.Gegov. A concept and methods for modelling complex technical systems with intelligent capabilities. Methodology of mathematical modelling. Bulgarian academy of sciences, 1992.

9. Avtanski A.,E.Gegov. Artifical Neural Networks with Built-in Logic-Statistical Functions. Tempus JEN 02538 BG-94, International Seminar on Advanced Control Theory, Varna, 10-11 June 1996, 118-120.

10. Gegov E. Analysis of Multifactor Plants and Control Systems under Uncertainty by Multivalued Probabilistic Logic. Национална конференция “Автоматика и информатика*97, София, 13-16 октомври 1997. 
11. Gegov E. Analysis of Intelligent Control Systems by Means of Multivalued Logic. Национална конференция “Автоматика и информатика*98, София, том 2 с.28, 1998.

12. Gegov E. Logical Method for Prediction of the Technical Productivity of Continues Processes in Open Mines. Национална конференция “Автоматика и информатика*98, София, том 6, с.5, 1998

13. Гегов Е. Управление систем при неполной информации методов селекции вероятных и размитых многозначных логических функций. Национална конференция “Автоматика и информатика*98, София, том 6, с.9, 1998

14. Gegov E. Composition of Multivalued Logical Probability Functions and their Application in Multistage Stocastic Systems, Automatica and Informatics, Journal, year XXXV, № 34/2001 page 68 .

15. Ganies B.R. Fuzzy and probability uncertainty logics, Information and Control 38, 154-169, 1978.

16. Gottwald Siegfried. Mehrwertige Logik. Eine Einfuhrung in Theorie und Anwendungen. Akademie Verlag Berlin 1989.

17. Krejser L., Gottwald S., Stelzner W. Nichtklassische Logik. Eine Einfuhrung, Berlin 1988 .

18. Zaden L.A. The concept of a Linguistic Variable and its Applications to Approximate Reasoning. American Elsevier Publishing Company, New York, 1973. 
